\title{
Configuration of dyslipidemia in patients with type 2 diabetes mellitus visiting tertiary care hospital Quetta-Pakistan
}

Shabbir Hussain Shah ${ }^{1}$, Muhammad Masood Tariq kiani ${ }^{1}$, Muhammad Aleem Akhter ${ }^{1}$, Tahir Hameed ${ }^{1 *}$, Farhat abbas Bokhari ${ }^{1}$, Zafarullah Khan ${ }^{1}$, Babar Hilal Ahmed ${ }^{1}$, Muhammad Yousaf ${ }^{1}$, Abdul Salam Shah ${ }^{2}$, Wardha Shamim Lodhi ${ }^{3}$, Hina Ishtiaq ${ }^{4}$, Noor ul Hassan ${ }^{1}$ and Anwar ur Rehman $^{1}$

1. Department of Physiology \& Endocrinology, CASVAB, University of Balochistan, Quetta-Pakistan

2. Department of Endocrinology, Bolan Medical Complex Hospital (BMCH) Quetta-Pakistan

3. Medicine Department, Sandeman Provincial Hospital (SPH) Quetta-Pakistan

4. Department of Bio Technology, SBK University Balochistan, Quetta

*Corresponding author's email: tahirquetta@hotmail.com

Citation

Shabbir Hussain Shah Muhammad Masood. Tariq kiani, Muhammad Aleem Akhter, Tahir Hameed, Farhat abbas Bokhari, Zafarullah Khan,Babar Hilal Ahmed,Muhammad Yousaf, Abdul Salam Shah, Wardha Shamim Lodhi, Hina Ishtiaq Noor ul Hassan1 and Anwar ur Rehman. Configuration of dyslipidemia in patients with type 2 diabetes mellitus visiting tertiary care hospital Quetta-Pakistan. Pure and Applied Biology. Vol. 8, Issue 1, pp288-294. http://dx.doi.org/10.19045/bspab.2018.700187

Received: 16/08/18 Revised: 06/11/18
Accepted: $10 / 11 / 18$ Online First: 14/11/18

\section{Abstract}

Dyslipidemia among others, is the profound threat for cardiovascular disorder in Type 2 Diabetes Mellitus (DM). Prompt recognition and management of dyslipidemia in Type $2 \mathrm{DM}$ can inhibit threats for atherogenic heart disease. The motivation behind the upcoming study was to uncover the irregularity of lipid profiles in Type 2 DM patients. Requisite statistics were taken from 242 patients ( 95 females, 147 male) suffering with Type 2 DM and registered in the Department of Endocrinology and Medicine at Bolan Medical Complex hospital (BMCH) and Sandeman Provincial Hospital (SPH) Quetta, Pakistan. The Result of lipid profiles indicated that statistical values for Total Cholesterol (TC), Triglyceride (TG), High Density Lipid Cholesterol (HDL-C), Low Density Lipid Cholesterol (LDL-C) and Very Low Density Lipid Cholesterol were (VLDL-C) 196.03 \pm 67.99, $256.69 \pm 173.56,36.11 \pm 9.95,118.29 \pm 56.41$ and $49.80 \pm$ $33.44 \mathrm{mg} / \mathrm{dl}$ in female subjects respectively. In male subjects the mean-values for TC, TG, HDL-C, LDL$\mathrm{C}$ and VLDL-C were $222.12 \pm 69.24,339.37 \pm 260.73,34.73 \pm 7.10,119.08 \pm 42.10$ and $68.46 \pm 54.42$ $\mathrm{mg} / \mathrm{dl}$ respectively. FPG demonstrated profoundly positive correlation with RPG. TG displayed a profoundly negative correlation with HDL, while positive correlation with VLDL, but HDL showed negative statistical correlation with LDL. The study disclosed communal lipid irregularities during diabetes prompted dyslipidemia i.e., elevated TC, TG, LDL-C and decreased HDL-C values. This abstraction advocates prevalence of hyperlipidemia over increased dominance of dyslipidemia.

Keywords: Cardiovascular disorders; Dyslipidemia; Type 2 diabetes mellitus

\section{Introduction}

Pakistan is the $6^{\text {th }}$ densely populated Country of the world [1]. In Pakistan, most people live 
in rural areas. Pakistan has tolerated deteriorated economic and epidemiologic alteration. Accelerating urbanization has directed to deskbound lifestyle, enhanced calorie food intake, greedy eating and less consuming. The said irritating habits doubled with the stressful conditions led towards the occurrence of Type 2 DM [2]. Type 2 DM is placed high amongst the top ten globally health emergencies worldwide, moreover is also placed amongst the top ten reasons of mortalities and combined with the other three most important Non Communicable Diseases (NCDs) (respiratory disorders, cardiovascular disease and cancer) is the reason for above $80 \%$ of all NCD mortalities. Approximately 39.5 million deaths out of the 56.4 million mortalities worldwide were because of NCDs in 2015 [3]. Furthermore, in the metropolitan population of Pakistan, people are exposed to polluted environment which in turn rises the metabolic disorders and diabetes mellitus. According to International Diabetic Federation (IDF) 2015, "415 million people had Type 2 DM and the number will expected to be 642 million in year 2040." Moreover, one person in two adults with Type $2 \mathrm{DM}$ is undiagnosed. Diabetes caused five million deaths in 2015; it exhibits that, in every six seconds a patients dies because of the complications of Type 2 DM. The occurrence of Type $2 \mathrm{DM}$ is increasing globally, One third of population is suffering with Type 2 $\mathrm{DM}$ are in low and middle income states. The WHO project reported increasing incidence of Type $2 \mathrm{DM}$ in progressing nations. Approximately 425 million individuals globally, or $8.8 \%$ of adults between the ages of 20 to 79 years, are predictable to have Type 2 DM. Approximately $79 \%$ population lives in low socio-economic states. The figure of patients with Type $2 \mathrm{DM}$ rises to 451 million if the age is raised between 18 to 99 years. If these developments are in progress, by 2045, 693 million individuals of age 18 to 99 years, or 629 million individuals of age 20 to 79 years, will be affected with Type 2 DM. People with Type 2 DM are at intensified threat of cardiovascular disease (CVD). High level of blood sugar leads toward the involvement of blood clotting disorders. Type $2 \mathrm{DM}$ is related with hypertension and dyslipidemia as well, which leads to amplified threat of cardiovascular problems such as angina, stroke, coronary artery disorders(CADs), peripheral artery disorders (PADs), myocardial infarction (MI), and congestive heart failure (CHF) [4]. The metabolic syndrome (MetS) is a group of threat features for CVD and Type 2DM, with hypertension, dyslipidemia (high TG and low HDL-C), raised PG and abdominal obesity [5]. Though MetS is not responsible for such established risk features as age, gender and smoking, yet the patients diagnosed with MetS have a two-fold increase of CVD hazard and a five-fold rise in progress of Type 2 DM. Type 2 DM is an established threat feature for cardiovascular diseases (CVD). As compared with non-diabetic persons, diabetic patients have two to four times escalated hazard for stroke and death from heart disease [6]. Dyslipidemia, a wellknown threat feature for CVD, is amazingly common in Type 2 DM patients, disturbing about $50 \%$ of this populace [7]. As dyslipidemia is a notable threat feature for macro vascular problems in Type $2 \mathrm{DM}$ patients $[8,9]$. Disruption in lipid metabolism seems a pre-mature stage in the progress of Type 2 DM, possibly prior to disorder by few years [10]. Besides, the various constituents of diabetic dyslipidemia (plasma Lipid and Lipoprotein irregularities) are said to be metabolic related [11]. The dyslipidemia, linked with insulin contention (as well mentioned as atherogenic dyslipidemia), is considered by moderate-increase in TG levels in serum carried in VLDL constituent, reduced HDL-C levels in serum carried in small HDL particles, and LDL-C levels in 
serum that do not change noticeably from those of individual patients without Type 2 DM [12].

CVD is a main source of mortality and disability in individuals with Type 2 DM. Amongst middle-age individuals with Type 2 DM living in average economic states, up to 27 individuals out of 1,000 die from CVD every year; a 3rd of them die from stroke, and a quarter expire from coronary artery disease [13]. The rationale of this study was to highlight and evaluate the configuration of dyslipidemia in patients with Type $2 \mathrm{DM}$ in Quetta, Pakistan.

\section{Materials and methods}

This was a cross-sectional questionnairebased study. Ethical approval was acquired from the Ethical Committee, University of Baluchistan, and Quetta. (Letter number: 256-3/CASVAB Dated $8^{\text {th }}$ June 2017). The study was conducted in Endocrinology department of Bolan Medical Complex hospital (BMCH) form July 2017 to June, 2018. Subjects of both genders, above 18 years of age were included. Subjects meeting the inclusion criteria were briefed about the study and informed consent was obtained from those agreeable to participate. Study participants were interviewed by a direct interview and the information was entered in a semi-structured questionnaire to get the following details: demographic characteristics and Using patients' clinic files, the following clinical data were recorded. i.e. FPG, RBG, HbA1C, lipid profile and other measures.

1. Group A consisted of female T2 DM

2. Group B consisted of male T2 DM

Group A and B patients were diagnosed cases of T2 DM. Patients were selected on the basis that there was no significant difference in their clinical characteristics and glycemic status. One hundred forty-seven (147) patients were males and ninety-five (95) patients were females.

\section{Exclusion criteria}

Patients were excluded from the study on the following conditions:

1. If they were less than 18 year of age, had T1DM, GDM, and steroid induced diabetes.

2. Patients suffering from other causes of secondary dyslipidemia such as hypothyroidism, cystic fibrosis, patients taking contraceptives.

\section{Statistical analysis}

Statistical analysis was performed using the statistical package for the social sciences (SPSS) software version 23. Descriptive analysis was used to analyze the demographic data. The descriptive statistic included mean, median, frequency and standard deviation. The data were analyzed Correlative studies (Person's correlation) that executed between the variables of FPG, RPG and lipid profile (TC, TG, HDL-C, LDL-C\& VLDL-C) by using SPSS.

\section{Results}

In this study, type 2 DM patients $(n=242)$ were included comprising of adult male $(n=147)$ and adult female $(n=95)$ patients (Table 1) Female patients, the age range and mean age were 23-76 years and female patients mean age $48.45 \pm 12.42$, whereas in male patients the age range and mean age were $25-78$ years and $48.10 \pm 12.79$ years, respectively. Outcomes of the blood glucose level (Table 2) revealed that all patients were hyper glycemic. In female patients FPG statistical range and mean-value were 73-410 $\mathrm{mg} / \mathrm{dl}$ and $171.56 \pm 68.17 \mathrm{mg} / \mathrm{dl}$, whereas in female patient's RPG statistical range and mean value were $148-551 \mathrm{mg} / \mathrm{dl}$ and 284.37 $\pm 104.72 \mathrm{mg} / \mathrm{dl}$. The consequent outcome displayed the FPG in male patients, the statistical range and mean-value were 67-418 $\mathrm{mg} / \mathrm{dl}$ and $167.85 \pm 60.44 \mathrm{mg} / \mathrm{dl}$, whereas in males; the range and mean-value of RPG were $138-594 \mathrm{mg} / \mathrm{dl}$ and $279.63 \pm 104.85$ $\mathrm{mg} / \mathrm{dl}$ respectively (Table 2 ). It has been detected that certain patients have standard values FPG, but their RPG values was above 
the standard. Consequently, the values of FPG in certain patients evinced approximately standard or precise, whilst uncontrolled patients were also there. Results of lipids profile disclosed (Table 3 ) that the mean-values for TC, TG, HDL-C, LDL-C and VLDL-C were 196.03 $\pm 67.99,256.69$ \pm 173.56 , and $36.11 \pm 9.95,118.29 \pm 57.41$ and $49.80 \pm 33.44 \mathrm{mg} / \mathrm{dl}$ in female subjects respectively. The mean values for $\mathrm{TC}, \mathrm{TG}$, HDL-C, LDL-C and VLDL-C were 222.12 \pm $69.24,339.37 \pm 260.73,34.73 \pm 7.10,119.08$ \pm 42.10 and $68.46 \pm 54.42 \mathrm{mg} / \mathrm{dl}$ in the male subjects respectively. In correlation studies, (Table 4) FPG exhibited noteworthy positive correlation with RPG $(\mathrm{P}<0.001)$. The statistical correlation of TC with TG, LDL-C and VLDL-C at significance level $(\mathrm{P}<0.001)$ were positive. TG exhibited an important negative statistical correlation with HDL at $(\mathrm{P}<0.01)$, whereas very expressive positive correlation noticed with VLDL-C at $(\mathrm{P}<0.001)$, but, HDL-C exhibited a negative statistical correlation with VLDL-C at $(\mathrm{P}<0.01)$.

\section{Discussion}

The objective of this abstraction has to define the incidence, configuration and prognosticators of atherogenic dyslipidemia in Type 2DM patients. The study was conducted in Bolan Medical Complex hospital $(\mathrm{BMCH})$ of Quetta, Pakistan. The results showed that maximum no of the patients had above the standard serum TC, TG, LDL-C and below the standard level of serum HDL-C than the cut off values recommended by the National cholesterol education program and (NCEP) Adult Treatment panel III (ATP III) [2]. Irregular lipids profile in the Type $2 \mathrm{DM}$ patients were not shocking. Deficiency or resistance of Insulin raised the rate of lipolysis in adipocytes and onset of free-fatty acids (FFAs) into the liver resultant into overproduction of triglyceride rich lipoproteins. Furthermore, there is late filtration of such lipoproteins because of reduced action of the endothelial bound enzyme lipoprotein lipase [14]. There was no important variance among the serum levels of the lipid (TC, TG, HDL$\mathrm{C}$, LDL-C and VLDL-C) for males and females $[15,16]$.

Table 1. Frequency distribution of Type-2 DM in adult male \& female patients in Quetta region

\begin{tabular}{|c|c|c|c|}
\hline \multicolumn{2}{|c|}{ Description } & Frequency & Percent \\
\hline \multirow{4}{*}{} & Female & 95 & 39.30 \\
\cline { 2 - 4 } & Male & 147 & 60.70 \\
\cline { 2 - 4 } & Total & 242 & 100.00 \\
\hline
\end{tabular}

Table 2. The Standard and Calculated Values of Fasting Plasma Glucose (FPG) and Random Plasma glucose (RPG) in adult male and female patients of Quetta region

\begin{tabular}{|c|c|c|c|c|c|c|}
\hline & Fasting & & & Random & & \\
\hline Gender & $\begin{array}{l}\text { Normal } \\
\text { Value }\end{array}$ & $\begin{array}{c}\text { Calculated } \\
\text { Value }\end{array}$ & Mean & $\begin{array}{l}\text { Normal } \\
\text { Value }\end{array}$ & $\begin{array}{c}\text { Calculated } \\
\text { Value }\end{array}$ & Mean \\
\hline Female & $70-125$ & $73-410$ & 171.56 & $>200$ & $148-551$ & 284.37 \\
\hline Male & $70-125$ & $67-418$ & 167.85 & $>200$ & $138-596$ & 279.63 \\
\hline
\end{tabular}


Table 3. The Standard and Calculated Values of TC, TG, HDL-C, LDL-C \& VLDL-C in Adult male and female patients of Quetta region

\begin{tabular}{|c|c|c|c|c|c|c|}
\hline $\begin{array}{c}\text { Lipid } \\
\text { Parameters }\end{array}$ & $\begin{array}{c}\text { Fomale } \\
\text { Values }\end{array}$ & $\begin{array}{c}\text { Calculated } \\
\text { Value }\end{array}$ & Mean & $\begin{array}{c}\text { Mormal } \\
\text { Value }\end{array}$ & $\begin{array}{c}\text { Calculated } \\
\text { Value }\end{array}$ & Mean \\
\hline $\begin{array}{c}\text { Total } \\
\text { Cholesterol }\end{array}$ & $<200$ & $56-668$ & 196.03 & $<200$ & $90-422$ & 222.12 \\
\hline Triglyceride & $50-150$ & $56-1140$ & 256.6 & $50-150$ & $53-991$ & 339.37 \\
\hline $\begin{array}{c}\text { HDL- } \\
\text { Cholesterol }\end{array}$ & $45-65$ & $17-60$ & 36.1 & $45-65$ & $18-63$ & 34.73 \\
\hline $\begin{array}{c}\text { LDL- } \\
\text { Cholesterol }\end{array}$ & $<100$ & $41-415$ & 118.29 & $<100$ & $39-229$ & 199.08 \\
\hline $\begin{array}{c}\text { VLDL- } \\
\text { Cholesterol }\end{array}$ & $15-30$ & $11-228$ & 49.80 & $15-30$ & $11-223$ & 68.46 \\
\hline
\end{tabular}

FPG $=$ Fasting plasma glucose, RPG Random plasma glucose, $\mathrm{TC}=$ Total cholesterol, $\mathrm{TG}=$ Triglycerides, HDL= High density cholesterol, LDL=Low density cholesterol, VLDL= Very low-density cholesterol

Table 4. Statistical Correlation between FPG, RPG, TC, TG, HDL, LDL, VLDL

\begin{tabular}{|c|c|c|c|c|c|c|}
\hline & R P G & T C & T G & H D L & LDL & VL DL \\
\hline F P G & $.704^{* *}$ & -.054 & -.036 & -.013 & .002 & -.027 \\
\hline R P G & - & -.081 & -.060 & .012 & .036 & -.051 \\
\hline T C & - & - & $.706^{* *}$ & -.023 & $.650^{* *}$ & $.719^{* * *}$ \\
\hline T G & - & - & - & $-.356^{* *}$ & $.182^{* *}$ & $.977^{* *}$ \\
\hline H D L & - & - & - & - & .055 & $-.338^{* *}$ \\
\hline L D L & - & - & - & - & - & $.172^{* *}$ \\
\hline
\end{tabular}

= Correlation is significant at the level 0.01(2-tailed)

$\mathrm{FPG}=$ Fasting plasma glucose, $\mathrm{RPG}$ Random plasma glucose, $\mathrm{TC}=$ Total cholesterol, $\mathrm{TG}=\mathrm{Triglycerides}, \mathrm{HDL}=\mathrm{High}$ density cholesterol, LDL=Low density cholesterol, VLDL= Very low-density cholesterol

In Type 2 DM, dyslipidemia is significant and communal threat feature for coronary heart disorders (CHD) that is a foremost reason of morbidity and mortality globally [17]. Solid confirmation has established that Type $2 \mathrm{DM}$ patients have a related hazard of heart attack as patients without Type 2 DM who previously had a heart attack. [18]. Adult Treatment panel III (ATP III) labelled diabetes mellitus as coronary heart disease (CHD) threat equal and LDL was recognized the first significance of lipid lowering [19]. Current developments have acknowledged the compound chemistry of diabetic dyslipidemia that is a bunch of potentially atherogenic lipids and lipoproteins irregularities [20]. The most dominant atherogenic constituents are:

1. Small dense LDL-C,

2. Residual particles, and
3. The low levels of HDL-C with its uncomplimentary compositional variations. Co-occurrence of the said features strongly magnifies the lipid gathering in arterial vessels and the plaque constitution [20, 21]. American Diabetes Association (ADA) and European Association for the Study of Diabetes (EASD) combined scientific statement advocates Lifestyle administration (includes healthy diet, physical activities and quitting the smoking) as a first tool for the managing of Type 2DM, with objectives of weight reduction and decrease of cardiovascular hazards [14]. Physical activities are significant in the avoiding the development of Type 2DM in patients with IGT, and for the regulation of glucose level and interrelated CVD problems [15]. Aerobic and resistance exercise ameliorate insulin 
action and PG, lipid profile, Blood Pressure (BP) and cardiovascular hazards [16].

\section{Conclusions and recommendation}

Present study has revealed common lipid irregularities throughout diabetes induced dyslipidemia are: hyper triglyceridemic, hyper cholesterolemia and raised LDL-C. Outcomes have suggested high occurrence of dyslipidemia, which may be playing a main character in the enhancement of CVD amongst the Type 2 DM patients. Ideal management of the patients with Type $2 \mathrm{DM}$ should comprise with repetitive checking of plasma glucose and lipids profile. Life style modifications such as physical exercise and reduction in weight is required to be adopted in the first step, coupled with medication/management with lipid reducing treatments. The supreme management with anti-diabetic drugs to attain rational glycemic control is encouraged to go with lipid lowering drugs.

The lifestyle management i.e. physical activities, smoking cessation, healthy eating and weight loss as first step for the management of dyslipidemia in type 2 diabetes mellitus.

\section{Authors' contributions}

Conceived and designed the experiments: $\mathrm{SH}$ Shah, MMT Kiani, WS Lodhi, H Ishtiaq, NU Hassan \& AU Rehman, Performed the experiments: MA Akhter \& SH Shah, Analyzed the data: Z Khan, BH Ahmed \& M Yousaf, Contributed materials/ analysis/ tools: AS Shah \& WS Lodhi, Wrote the paper: T Hameed, FAB Bokhari.

\section{References}

1. Baker P \& Friel S (2014). "Processed foods and the nutrition transition: evidence from Asia. Obesity Reviews 15(7): 564-577.

2. $\mathrm{Hu}$ FB (2011). Globalization of diabetes: the role of diet, lifestyle, and genes. Diabetes Care 34(6): 1249-1257.
3. DeFronzo RA, et al. (2015). International Textbook of Diabetes Mellitus, 2 Volume Set, John Wiley \& Sons.

4. You WP \& Henneberg M (2016). Type 1 diabetes prevalence increasing globally and regionally: the role of natural selection and life expectancy at birth. BMJ Open Diabetes Res and Care 4(1): $\mathrm{e} 000161$.

5. Alberti K, et al. (2009). Harmonizing the metabolic syndrome: a joint interim statement of the international diabetes federation task force on epidemiology and prevention; national heart, lung, and blood institute; American heart association; world heart federation; international atherosclerosis society; and international association for the study of obesity. Circulation 120(16): 1640-1645.

6. Wu L \& Parhofer KG (2014). "Diabetic dyslipidemia. Metabol Clin and Exper 63(12): 1469-1479.

7. Saydah SH, et al. (2004). Poor control of risk factors for vascular disease among adults with previously diagnosed diabetes. Jama 291(3): 335-342.

8. Turner R., et al. (1998). Risk factors for coronary artery disease in non-insulin dependent diabetes mellitus: United Kingdom Prospective Diabetes Study (UKPDS: 23). BMJ 316(7134): 823-828.

9. Farmer JA (2008). Diabetic dyslipidemia and atherosclerosis: evidence from clinical trials. Curr Diab Rep 8(1): 71-77.

10. Adiels M, et al. (2008). Overproduction of very low-density lipoproteins is the hallmark of the dyslipidemia in the metabolic syndrome. Arterios Throm and Vasc Biol 28(7): 1225-1236.

11. Taskinen MR (2005). Type 2 diabetes as a lipid disorder. Curr Mol Med 5(3): 297308.

12. Krentz AJ (2003). Lipoprotein abnormalities and their consequences for patients with type 2 diabetes. Diabetes, Obesity and Metabol 5(S1). 
13. Imamura F, et al. (2015). Consumption of sugar sweetened beverages, artificially sweetened beverages, and fruit juice and incidence of type 2 diabetes: systematic review, meta-analysis, and estimation of population attributable fraction. $B M J$ 351: h3576.

14. Inzucchi SE, et al. (2012). Management of hyperglycaemia in type 2 diabetes: a patient-centered approach. Position statement of the American Diabetes Association

15. Sluik D, et al. (2012). Physical activity and mortality in individuals with diabetes mellitus: a prospective study and metaanalysis. Archives of Inter Med 172(17): 1285-1295.

16. Seger J, et al. (2014). Obesity algorithm, presented by the American Society of Bariatric Physicians.

17. Turner R, et al. (1998). Risk factors for coronary artery disease in non-insulin dependent diabetes mellitus: United Kingdom Prospective Diabetes Study (UKPDS: 23). BMJ 316(7134): 823-828.
18. Malmberg K, et al. (2000). Impact of diabetes on long-term prognosis in patients with unstable angina and non-Qwave myocardial infarction: results of the OASIS (Organization to Assess Strategies for Ischemic Syndromes) Registry. Circulation 102(9): 1014-1019.

19. Expert Panel on Detection, E (2001). Executive summary of the Third Report of the National Cholesterol Education Program (NCEP) expert panel on detection, evaluation, and treatment of high blood cholesterol in adults (Adult Treatment Panel III). Jama 285(19): 2486.

20. Syvänne M \& Taskinen MR (1997). "Lipids and lipoproteins as coronary risk factors in non-insulin-dependent diabetes mellitus. The Lancet 350: S20-S23.

21. Ginsberg HN (2002). New perspectives on atherogenesis: role of abnormal triglyceride-rich lipoprotein metabolism. Circulation 106(16): 2137-2142. 